\title{
Differential Analysis of 0-(2- hydroxypropyl) cellulose by Using Two-Dimensional 1H-NMR Spectroscopy
}

\author{
Naotaka Sakamoto ${ }^{1}$, Edmont Stoyanov ${ }^{2 *}$ \\ ${ }^{1}$ Nippon Soda Nihongi, 950 Fujisawa, Nakago-ku, Joetsu, Niigata 949-2392, Japan \\ ${ }^{2}$ Nisso Chemical Europe, Berliner Allee 42, 40212 Duesseldorf, Germany
}

Received: 19 December, 2019

Accepted: 28 February, 2020

Published: 02 March, 2020

*Corresponding author: Edmont Stoyanov, Nisso Chemical Europe, Berliner Allee 42, 40212 Duesseldorf, Germany, Tel: +49-211-130 69 473; Mobile: +49-151-20 0301 88; Fax: +49-211-32 82 31;

E-mail: stoyanov@nisso-chem.de

ORCiD: https://orcid.org/0000-0002-1571-9259

Keywords: HPC: O-(2-hydroxypropyl) cellulose; Proton-proton cross-relaxation; Nuclear overhauser effect; 3D structure; molecular weight and solvent importance

https://www.peertechz.com

Check for updates

\section{Abstract}

Two-dimensional ${ }^{1} \mathrm{H}$-NMR is used to determine the intra-molecular interactions of $\mathrm{O}$-(2-hydroxypropyl) cellulose (HPC) in aqueous $\left(\mathrm{D}_{2} \mathrm{O}\right)$, DMF and $\mathrm{DMSO}$ solutions. Four grades HPC with different molecular weights are analyzed by using NOESY (Nuclear Overhauser Effect Spectroscopy) for proton-proton cross-interactions. A strong dependence of the polymer chain structure on the HPC Molecular Weight (MW) is overserved. The lower MW HPCs exist in solutions as a more linear chain showing less proton-proton interactions whereas the higher MW HPCs are more twisted and bended and form a tangled molecule mess with very intensive interactions between the $-\mathrm{CH}_{3},-\mathrm{CH}_{2}$ - and $-\mathrm{C}-\mathrm{H}$ protons. From all the grades, the ultra-low molecular weight HPC-UL $(\mathrm{MW} 20,000)$ revealed the weakest proton-proton cross-relaxations and exists in solutions probably only as an almost linear chain polymer.

\section{Introduction}

The solubility enhancement of poorly soluble drugs is known to be one of the biggest challenges in the pharmaceutical technology. The permanently increasing number of APIs (Active Pharmaceutical Ingredient) with low solubility creates the need of new polymers that enhance the API solubility and bioavailability. Usually used as a binder, the 0-(2-hydroxypropyl) cellulose (Hydroxypropyl Cellulose, HPC) revealed a new and unexpected activity as solubility enhancer for poorly soluble drugs. Recent papers described the successful application of HPC as solubilizing polymer for nano-suspensions and amorphous solid dispersions [1-3]. Ito and Konnerth $[1,2]$, described in two papers the application of HPC and copovidone for the preparation of nano-suspensions where the best results were achieved with the low molecular weight HPC-SSL. Zecevic et al., [3], reported the application of HPC-SSL in combination with HPMCAS as a solubilizer for Dipyridamole and Griseofulvin, two poorly soluble drugs with rash precipitation under certain $\mathrm{pH}$ conditions. Prodduturi et al., [4], reported an investigation of different molecular weight HPCs in Hot Melt Extrusion (HME) with clotrimazole where the lowest MW HPC demonstrated better dissolution results than the higher MW HPCs. This was explained with the possible increased entanglement of the polymer chain and a slower polymer erosion. Ten years later Osawa et al., [5] and Sarode et al., [6], gave the same explanation for the better solubility and permeability results of sulindac [5] and felodipine [6], in HPC-SSL containing solid dispersions. A short time ago, some of us published the efficient performance of the ultra-low molecular weight HPC-UL as best milling aid and solubilizer for Izraconazole in aqueous nano-suspensions [7].

The reason for the much better functionality of the low mwt HPC as solubilizer for poorly soluble drugs is still not well clarified and a close look at the HPC structure in solution could give the answer of this question.

The chemical structure of hydroxypropyl cellulose was already investigated per ${ }^{1} \mathrm{H}$ and ${ }^{13} \mathrm{C}-\mathrm{NMR}[8,9]$. Kimura et al., [8], described detailed the Degree of Substitution (DS), Molecular Substitution (MS) and even the different reactivity of the hydroxyl groups in the cellulose molecule based on the ${ }^{13} \mathrm{C}-\mathrm{NMR}$ in $\mathrm{D}_{2} \mathrm{O}$ peaks integrals. By using the same carbon NMR method, Desai et al., [9], explained the different performance 
of HPCs with different cloud points also giving details on the ratio outer/single carbons vs inner carbons. These fundamental works assume the HPC molecular structure as independent of molecular weight and that the grade examined in the studies was assumed to be representative of the entire family of HPC molecular weights.

Based on the published information we cannot explain why only the low molecular weight HPC works as a drug solubilizer. No meaningful differences in the physico-chemical properties (solubility, DS, MS and inner/outer carbon ratio) between the different grades of this cellulosic ether can be found. In order to get better understanding in this phenomenon, we decided to investigate what happens with the dissolved HPC polymer chain in the space by using a special two-dimensional ${ }^{1} \mathrm{H}-\mathrm{NMR}$ analysis - Nuclear Oherhauser Effect (NOE). Standard ${ }^{1} \mathrm{H}$-NMR spectra show the proton spin-spin coupling due to chemical bonds, whereas NOE occurs through the space when the distance between two protons is less than $4.9 \AA$. Thus, by using NOESY (Nuclear Overhauser Effect Spectroscopy) we can gain information on atoms and groups that are in close proximity to each other in the same molecule. This NMR method has been already successfully used for the investigation of three-dimensional structures of many proteins and other macromolecules [10-14].

In the present work, we describe a differential analysis of four grades hydroxypropyl cellulose with different molecular weights (viscosities) by using NOESY in DMSO- $d_{6}, \mathrm{DMF}-d_{7}$ and $\mathrm{D}_{2} \mathrm{O}$.

\section{Experimental}

\section{Chemicals}

Hydroxypropyl cellulose (HPC) with average molecular weight of 140,000 (HPC-L), 100,000 (HPC-SL), 40,000 (HPC-SSL) and 20,000 (HPC-UL) were provided by Nippon Soda, Japan. All the HPC grades have similar physicochemical characteristics like Molecular Substitution (M.S.), Hydroxypropoxy Content (HPO) and outer methyl+single methyl to inner methyl ratio [6] (outer/inner) were selected for the measurements (Table 1). The only relevant difference is in the Molecular Weight (MW).

Deuterated dimethyl sulfoxide (DMSO- $\left.d_{6}, 99.9 \% \mathrm{D}\right)$ and deuterated dimethyl formamide (DMF- $d_{7}, 99.5 \%$ D) were purchased by FUJIFILM Wako Pure Chemical Corporation, Japan. Deuterium oxide $\left(\mathrm{D}_{2} \mathrm{O}, 99.8 \% \mathrm{D}\right)$ was purchased by Tokyo Chemical Industry, Japan.

\section{Sample preparation}

For DMSO- $\mathrm{d}_{6}$ and DMF- $d_{7}$, in order to avoid the $\mathrm{OH}$ groups exchange with residual $\mathrm{H}_{2} \mathrm{O}$, the samples were prepared as follow: a. preliminary weighted amount of HPC was dried at $45^{\circ} \mathrm{C}$ overnight, then placed in a desiccator over $\mathrm{CaCl}_{2}$ for 30min under vacuum; b. the sample was then dissolved in the deuterated solvent $(0.5 \%)$ at room temperature under nitrogen atmosphere. For deuterated water $\left(\mathrm{D}_{2} \mathrm{O}\right)$, where the residual $\mathrm{H}_{2} \mathrm{O}$ doesn't play an important role, the sample preparation involves weighting and preparing of a $0.5 \%$ solution.

\section{Equipment \& measurement conditions}

Bruker Biospin AVANCE III HD 500 Onebay was used for the measurements: mixing time $0.3 \mathrm{~s}$; number of scans 8 . Tetramethyl silane $\left(\mathrm{Me}_{4} \mathrm{Si}\right)$ was used as an internal standard.

\section{Results and discussion}

The hydroxypropyl cellulose is a cellulosic ether that is composed of approximately $25-30 \%$ cellulose and $70-75 \%$ polypropylene oxide (HPO content Table 1, Figure 1).

Table 1: Physico-chemical Characteristics of HPC.

\begin{tabular}{|c|c|c|c|c|}
\hline HPC & MW $^{\mathbf{a}}$ & M.S. & HPO(\%) & Outer/lnner \\
\hline L & $1,40,000$ & 3.83 & 74.8 & 1.11 \\
\hline SL & $1,00,000$ & 3.62 & 73 & 1.13 \\
\hline SSL & 40,000 & 3.67 & 73.4 & 1.1 \\
\hline UL & 10,000 & 3.35 & 70.5 & 1.07 \\
\hline
\end{tabular}

aGPC method; average value. bJP17 method.

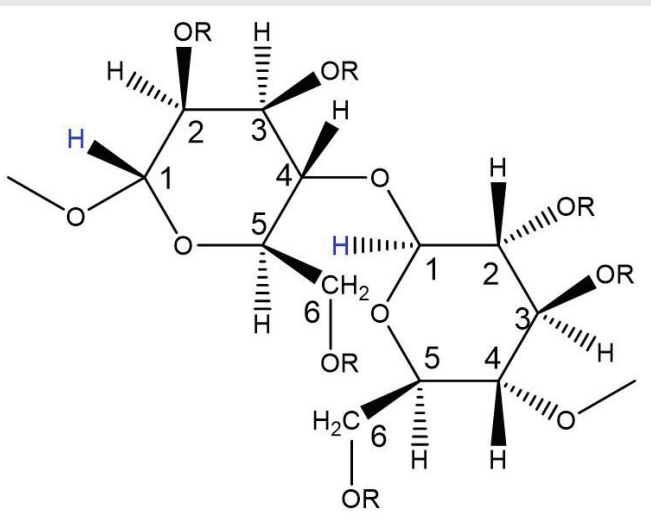

$\mathrm{R}=-\mathrm{CH}_{2}\left(\mathrm{CH}_{3}\right) \mathrm{CH}-\mathrm{O}-$ or $-\mathrm{CH}_{2}\left(\mathrm{CH}_{3}\right) \mathrm{CH}-\mathrm{OH}$

Figure 1: Idealized chemical structure of HPC.

The cellulose bone of the polymer chain is responsible for some rigidity and hydrophilicity of the molecule, whereas the side polypropylene oxide chain for some hydrophobicity and flexibility.

The possible theoretical proton-proton cross-relaxations in HPC-solutions are summarized in Figure 2.

Depending on the linearity of the chain and its position in the space, the intensity of the interactions can vary.

\section{${ }^{1} \mathrm{H}-\mathrm{NMR}$ for HPC-L, SL, SSL and UL}

The chemical shifts of the ${ }^{1} \mathrm{H}$-NMR spectra for all HPC grades measured in DMSO- $d_{6}, \mathrm{DMF}-d_{7}$ and $\mathrm{D}_{2} \mathrm{O}$ are given in Table 2.

Firstly, we have measured the ${ }^{1} \mathrm{H}$-NMRs in deuterated organic solvents that have no exchangeable protons: Dimethyl Sulfoxide (DMSO) and Dimethyl Formamide (DMF), where the $\mathrm{O}-\mathrm{H}$ protons cannot be exchanged and show own peak in the spectrum. The samples were preliminary dried down to avoid 
any $\mathrm{O}-\mathrm{H}$ exchange with the residual water. Figure 3 shows the ${ }^{1} \mathrm{H}-\mathrm{NMR}$ spectrum of HPC-L in DMSO- $d_{6}$ (as example) with the peaks of the different protons.

The methyl groups appear as singlet at 1.02ppm whereas the methylene groups $\left(-\mathrm{O}-\mathrm{CH}_{2}-;-\mathrm{O}-\mathrm{CH}\left(\mathrm{CH}_{3}\right)-\mathrm{CH}_{2}-\mathrm{O}-\right.$, cel$\left.\mathrm{CH}_{2}-\mathrm{O}-\right)$, inner and outer alpha-protons $\left(\mathrm{CH}_{3}-\mathrm{C}-\mathrm{H}, \mathrm{HO}-\right.$ $\mathrm{CH}\left(\mathrm{CH}_{3}\right)-\mathrm{CH}_{2}^{-}$) and cellulose protons (cel- $\mathrm{H}$ from $\mathrm{C} 2, \mathrm{C} 3$ and C4) are low-field shifted as a multiplet at 3.05-3.89ppm. For this study, it was not necessary to distinguish between the protons of tertiary and secondary carbons in this multiplet since their interaction with the protons of the other functional groups is identical. The $\mathrm{C} 1$ cellulose protons appears as a broad singlet at 4.39ppm. The hydroxyl protons, exchangeable with $\mathrm{D}_{2} \mathrm{O}$, appear as two broad singlets: one stronger at 4.42ppm and one weaker at $4.22 \mathrm{ppm}$. In order to define the exact position of the hydroxyl protons, deuterated water $\left(\mathrm{D}_{2} \mathrm{O}\right)$ was added to the sample solution. After the $\mathrm{D}_{2} \mathrm{O}$ addition, the peaks at 4.22 and 4.42ppm disappeared while the peak for the $\mathrm{C} 1$ proton remained unchanged at 4.39ppm (Figure 4).

The other HPC grades (SL, SSL, and UL) have identical ${ }^{1} \mathrm{H}-\mathrm{NMRs}$ with HPC-L in both DMSO- $d_{6}$ and DMF- $d_{7}$.

The ${ }^{1} \mathrm{H}$-NMR spectrum of HPC in aqueous solution looks slightly different compared to those in DMSO and DMF. The methyl groups appears as a sharp singlet at $1.18 \mathrm{ppm}$. The methylene groups $\left(-\mathrm{O}-\mathrm{CH}_{2}-;-\mathrm{O}-\mathrm{CH}\left(\mathrm{CH}_{3}\right)-\mathrm{CH}_{2}-\mathrm{O}-\right.$, cel$\left.\mathrm{CH}_{2}-\mathrm{O}-\right)$, inner $\left(\mathrm{CH}_{3}-\mathrm{C}-\mathrm{H}\right)$ and outer $\left(\mathrm{HO}-\mathrm{CH}\left(\mathrm{CH}_{3}\right)-\mathrm{CH}_{2}-\right)$ alpha-protons as well as the cellulose protons (cel- $H$ from

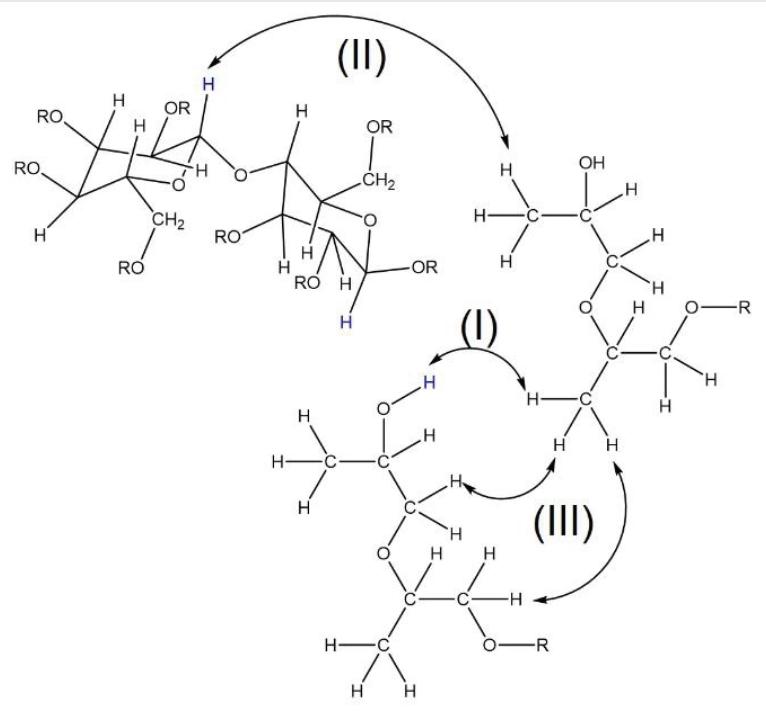

$\mathrm{R}=-\mathrm{CH}_{2}\left(\mathrm{CH}_{3}\right) \mathrm{CH}-\mathrm{O}-,-\mathrm{CH}_{2}\left(\mathrm{CH}_{3}\right) \mathrm{CH}-\mathrm{OH}$ or cellulose

Figure 2: Possible proton-proton cross-relaxations between the functional groups in the HPC molecule.

Table 2: ${ }^{1} \mathrm{H}-\mathrm{NMR}$ spectra of all grades HPC.

\begin{tabular}{|c|c|c|c|c|}
\hline \multirow[t]{2}{*}{ Solvent } & \multicolumn{4}{|c|}{$\delta$ in ppm } \\
\hline & $\mathrm{CH}_{3}$ & $\mathrm{CH}_{2}, \mathrm{CH}$ & HC1 & $\mathrm{OH}$ \\
\hline DMSO- $d_{6}$ & $1.02, \mathrm{~s}$ & $3.05-3.89, \mathrm{~m}$ & $4.39, \mathrm{br} . \mathrm{s}$. & $4.22,4.42$, br. s. \\
\hline DMF- $d_{7}$ & $1.07, \mathrm{~s}$ & $3.05-3.88, \mathrm{~m}$ & $4.56, \mathrm{br} . \mathrm{s}$. & $4.32,4.56$, br. $s$ \\
\hline $\mathrm{D}_{2} \mathrm{O}$ & $1.18, \mathrm{~s}$ & 3.24-3.98, m & 4.53, br. s. & not observable \\
\hline
\end{tabular}

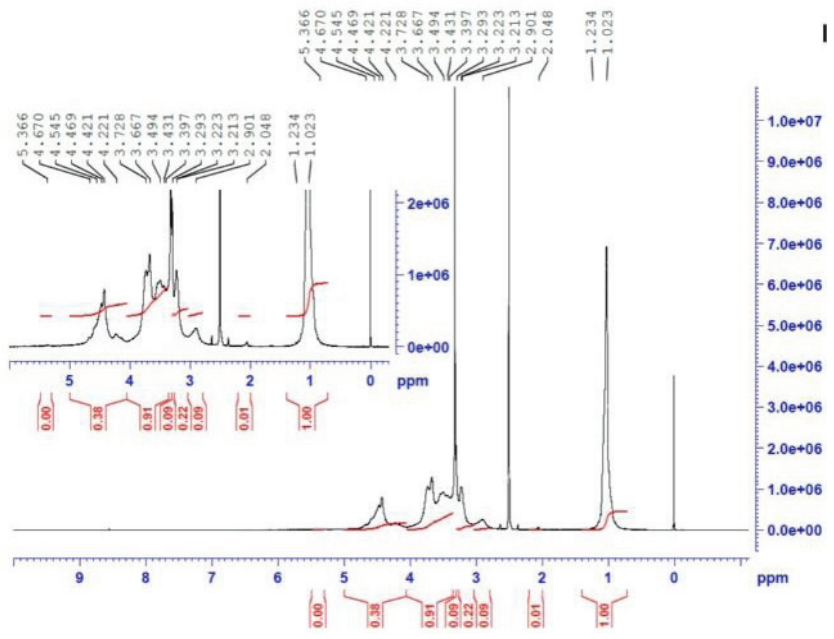

Figure 3: ${ }^{1} \mathrm{H}-\mathrm{NMR}$ spectrum of HPC-L in DMSO- $d_{6}$.

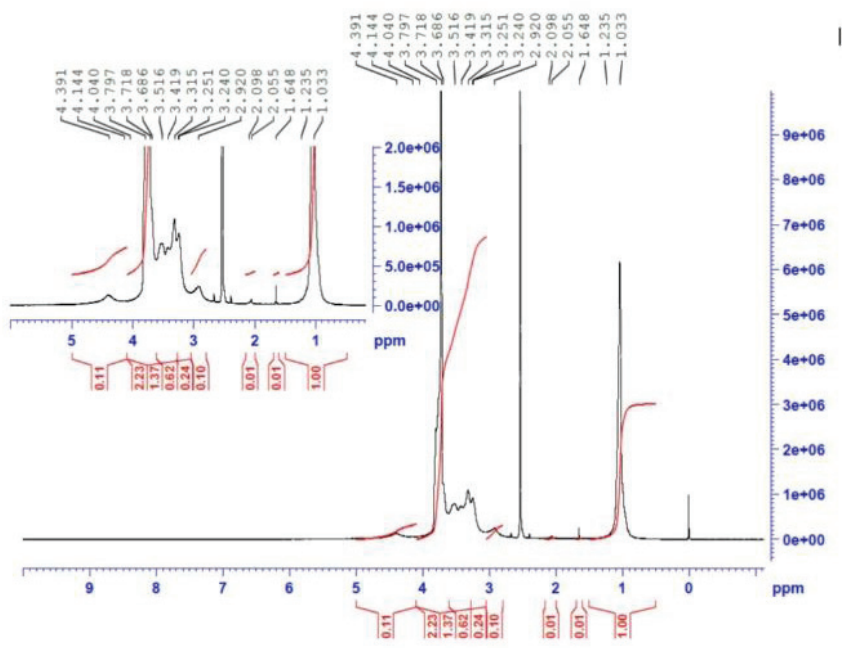

Figure 4: ${ }^{1} \mathrm{H}-\mathrm{NMR}$ spectrum of HPC-L in DMSO- $d_{6}$ after addition of $\mathrm{D}_{2} \mathrm{O}$.

C2, C3 and C4) are all low-field shifted as multiplet at 3.24$3.98 \mathrm{ppm}$. The $\mathrm{C} 1$ cellulose protons appears as a broad singlet at 4.53ppm. The hydroxyl protons cannot be observed because of $\mathrm{H}-\mathrm{D}$ exchange in solution with $\mathrm{D}_{2} \mathrm{O}$. Figure 5 shows the ${ }^{1} \mathrm{H}-\mathrm{NMR}$ of HPC-L as example.

All other HPC grades (SL, SSL, and UL) have identical ${ }^{1} \mathrm{H}-\mathrm{NMRs}$ with HPC-L.

\section{NOESYs of HPC-L, SL, SSL and UL NOESYs in DMSO-d}

The HPC with the highest molecular weight (L) showed multiple $\mathrm{H}-\mathrm{H}$ interactions between the functional groups (Figure 6). The strongest was the one between the protons of $\mathrm{CH}, \mathrm{CH}_{2}$ and $\mathrm{CH}_{3}$ groups (III and IV). This interaction was very strong, whereas it is independent on which proton was is the source. This speaks for a close proximity pf those groups in the space. The methyl protons demonstrated also interaction with the $\mathrm{C} 1$ protons form the cellulose moiety (II) as well as with the protons of the hydroxyl groups (I). This speaks for close distance between the inner and outer propoxyl groups and cellulose skeleton.

Citation: Sakamoto N, Stoyanov E (2020) Differential Analysis of O-(2- hydroxypropyl) cellulose by Using Two-Dimensional ${ }^{1} \mathrm{H}$-NMR Spectroscopy. Biomed Sci Eng 6(1): 010-015. DOI: https://dx.doi.org/10.17352/abse.000015 
The lower molecular weight grades HPC, revealed the same interactions however with decreased intensity, proportionally to the decrease of their molecular weight (Figure 7).

Generally, the intensity of all observed cross-relaxations (I-IV) was decreased with the decrease of the HPC molecular weight. The biggest difference was observed in the crossrelaxations between the hydroxyl and $\mathrm{C} 1$ cellulose protons and methyl group protons. We can conclude that the distance between the end-propoxy groups and cellulose skeleton is bigger at the lower molecular weight HPC. At HPC-UL (MW $10,000)$, the cross-relaxation was with the lowest intensity speaking for an almost linear, not much bended structure in DMSO solution.

\section{NOESYs in DMF-d,}

The ${ }^{1} \mathrm{H}-\mathrm{NMRs}$ in DMF- $d_{7}$ were almost identical with those in DMSO- $d_{6}$. Differences were observed in the NOE spectra where the proton-proton cross-relaxations in DMF were much stronger (Figure 8).

In DMF-solutions, the HPC molecule seems to be more tangled than in DMSO-solutions. Thus, in DMF, the functional groups appear to be in closer proximity in the space and interact stronger compared to DMSO. This is also confirmed by the NOESYs of the other HPC grades (SL, SSL and UL). As shown in Figure 9, also in DMF, a significant decrease of the $\mathrm{H}-\mathrm{H}$-crossrelaxations by decreasing the HPC MW was observed: HPC-UL (black) vs. HPC-SL (red).

\section{NOESYs in $\mathrm{D}_{2} \mathrm{O}$}

In deuterated water $\left(\mathrm{D}_{2} \mathrm{O}\right)$, all the observed proton-proton cross-relaxations were generally weaker compared to DMSO and DMF (Figure 10, example HPC-L).

As expected, proton-proton cross-relaxation between the hydroxyl and methyl group protons (I) was missing because of the exchanged $\mathrm{O}-\mathrm{H}$ proton. The intensity of the crossrelaxations III and IV in aqueous solutions are the strongest

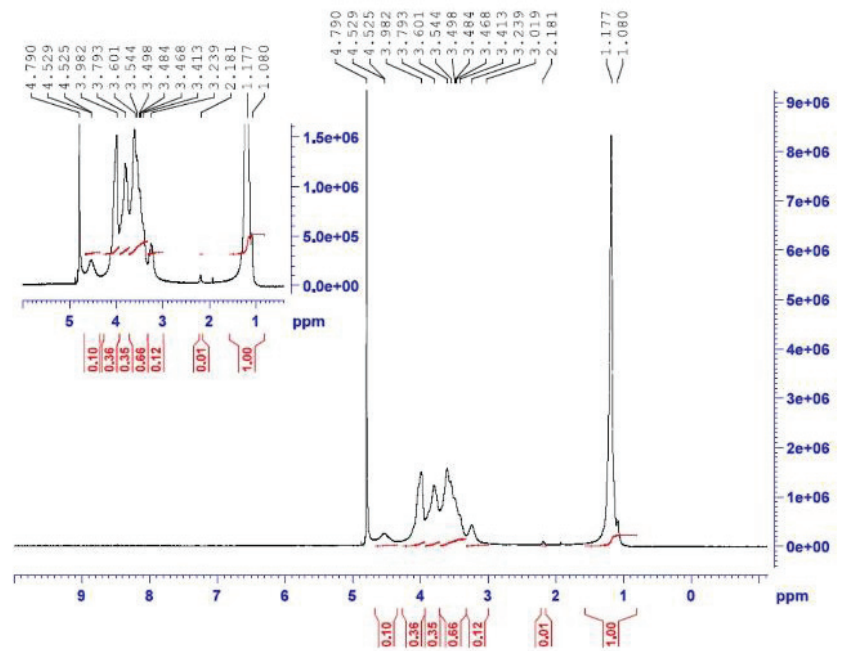

Figure 5: ${ }^{1} \mathrm{H}-\mathrm{NMR}$ spectrum of HPC-L in $\mathrm{D}_{2} \mathrm{O}$.

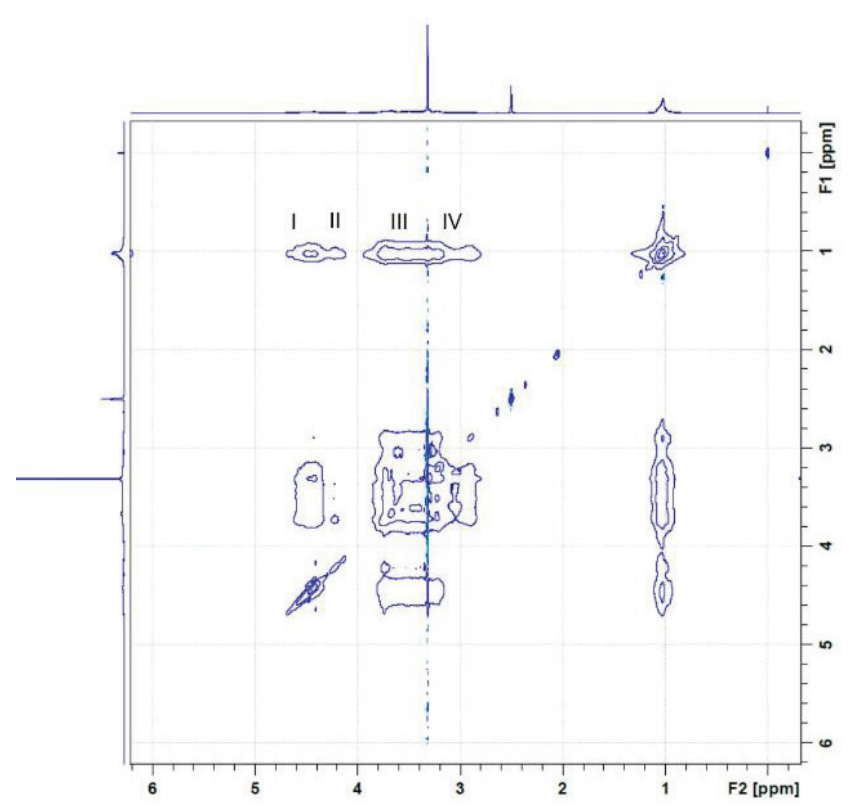

Figure 6: NOESY of HPC-L $(140,000)$ in DMSO- $d_{6}$.

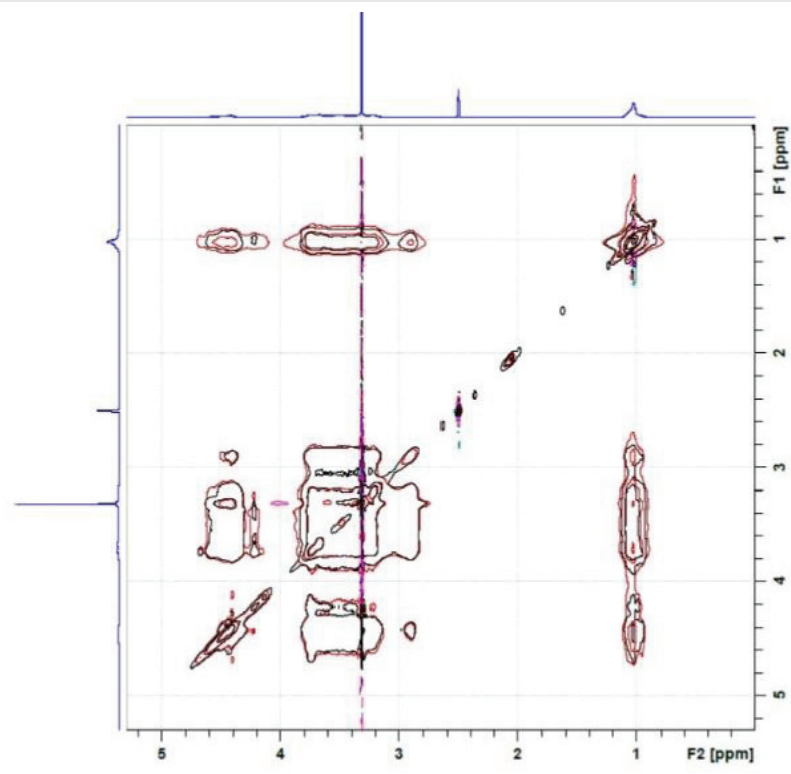

Figure 7: NOESY of HPC-SL $\left(100,000\right.$, red) and UL $\left(20,000\right.$, black) in DMSO- $d_{6}$ (as example).

like in DMSO and DMF whereas cross-relaxation II (C1 cellulose protons and methyl group protons) is weaker (Figure 10). Obviously in water, the HPC molecule is better dissolved, fully hydrated and stretched compared with the organic solvents (DMSO and DMF). The polymer chain is open giving a less tangled structure. Additionally, the distances between the methyl group protons and C1 cellulose protons (II) is bigger in water solutions than in DMSO and DMF that could facilitate interaction with other small molecules.

Like in the organic solvents DMSO and DMF, in aqueous solution all other HPC grades revealed a decrease of the protonproton cross-relaxations proportional to the decrease of their molecular weight/molecule length (Figure 11). 
In all solvents used, the ultra-low molecular weight HPCUL revealed the lowest intensity of the proton-proton crossrelaxation confirming a less tangled and bended structure in solutions compared with the other, higher MW HPC grades (L, SL and SSL, Figure 12).

In aqueous solutions, the observed differences in the intensity of the $\mathrm{CH}_{3}-\mathrm{CH}_{3}$ interactions (proton-proton crossrelaxations) at $1.1 \mathrm{ppm}$ caused by closer proximity of this functional groups in aqueous solution, confirm the observed minor differences in the cloud point of the different HPC grades. A stronger $\mathrm{CH}_{3}-\mathrm{CH}_{3}$ interaction with increase of the HPC molecular weight corresponds to a decrease of the cloud point (Figure 13).

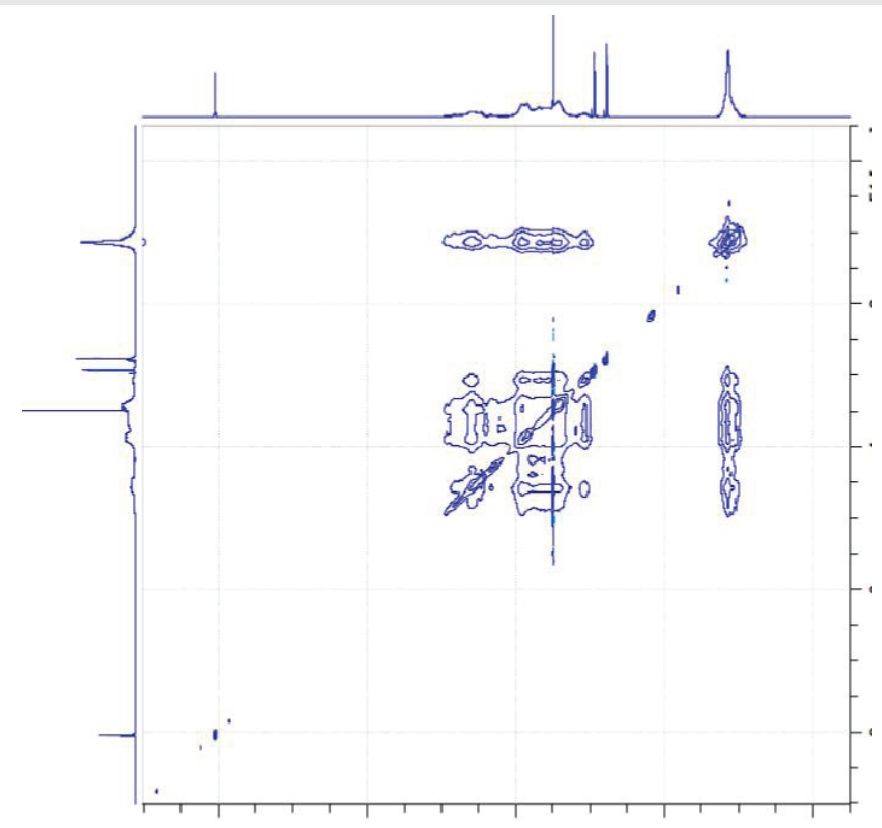

Figure 8: NOESY of HPC-L $(140,000)$ in DMF- $d_{7}$

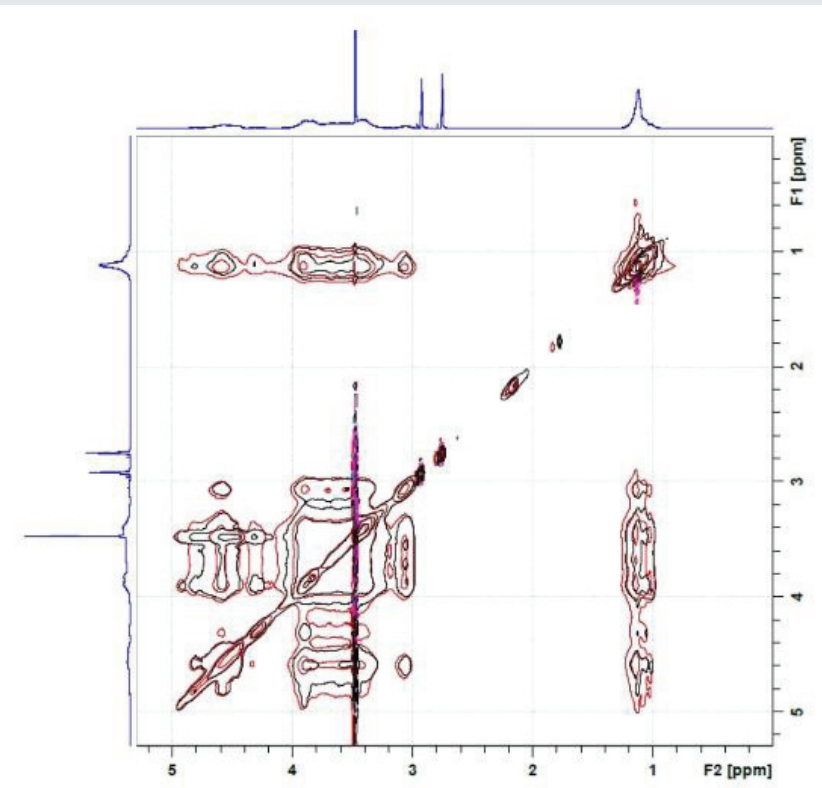

Figure 9: NOESY of HPC-SL $\left(100,000\right.$, red) and UL $\left(20,000\right.$, black) in DMF- $d_{7}$ (as example).

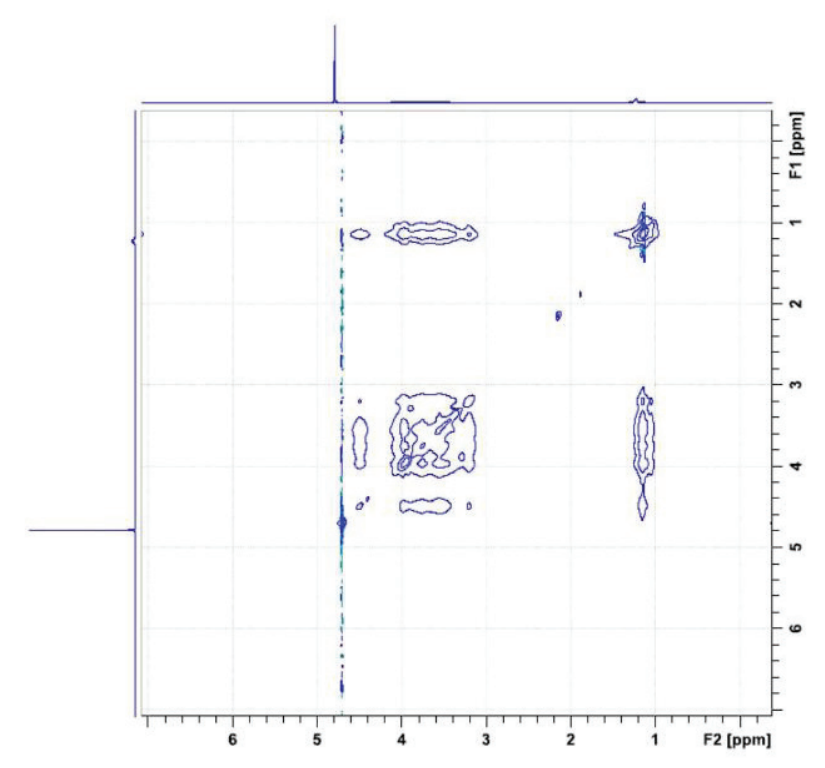

Figure 10: NOESY of HPC-L $(140,000)$ in $D_{2} 0$.

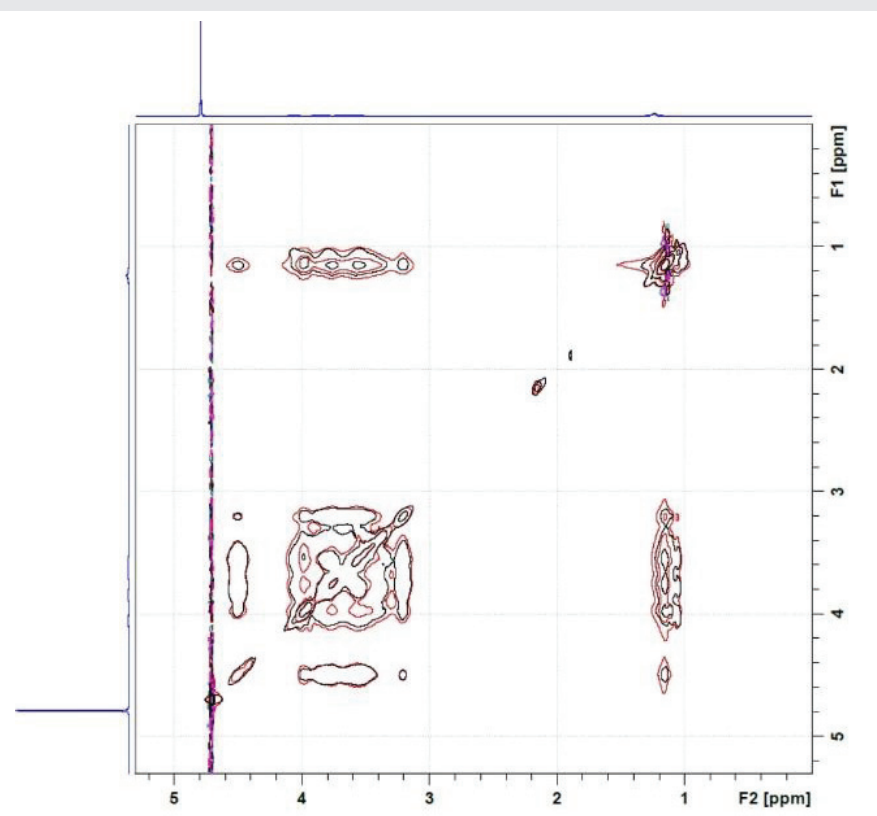

Figure 11: NOESY of HPC-SL $\left(100,000\right.$, red) and UL $\left(20,000\right.$, in black) in $D_{2} 0$ (example).

\section{Conclusions}

NOESY analysis of HPC solutions in organic solvents (DMSO and DMF) and aqueous solution revealed a relation between molecular weight (polymer chain length) and structure: low MW HPC exhibits more linear structure with low intensity proton-proton cross-relaxations between the functional groups protons. The aqueous HPC solutions favor a more "relaxed" and less tangled polymer chain with bigger space between the functional groups. In organic solvents, the HPC chain is more tangled and bended with multiple crossrelaxations. The differences in the HPC grades cloud point caused by the interactions between the methyl groups in the space is also proportional to their molecular weight. The 
HPC-L

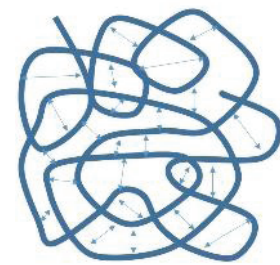

MW 140,000
HPC-SL

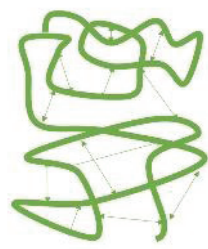

MW 100,000

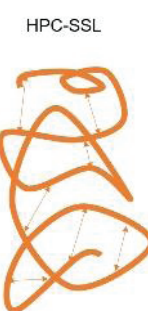

MW 40,000
HPC-UL

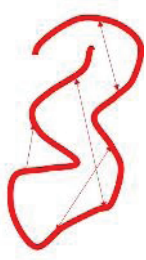

MW 20,000
Figure 12: Possible structures of HPC molecules in solution based on the NOESY spectra.
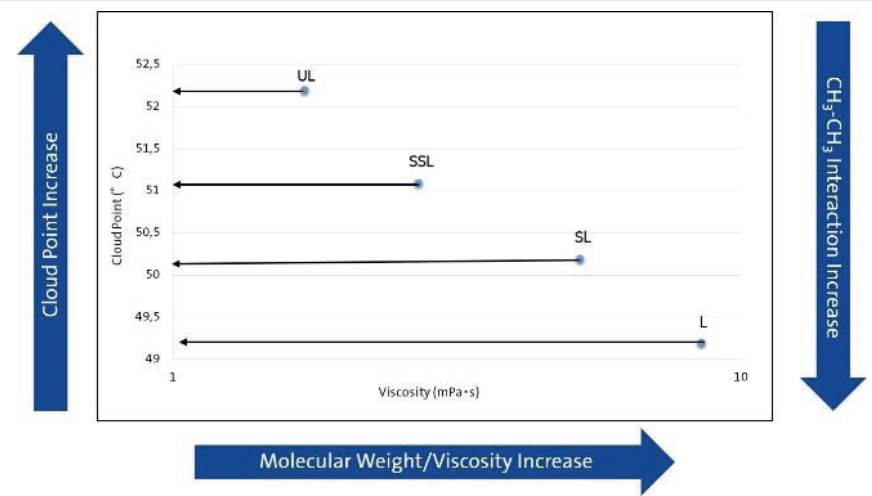

Figure 13: Molecular weight - cloud point dependence at the tested HPC grades.

ultra-low molecular weight HPC-UL demonstrated the lowest strength of molecular interactions due to a more linear polymer structure.

\section{References}

1. Ito A, Konnerth C, Schmidt J, Peukert W (2016) Effect of polymer species and concentration on the production of mefenamic acid nanoparticles by media milling. Eur J Pharm Biopharm 98: 98-107. Link: http://bit.ly/2PDnP14

2. Flach F, Konnerth C, Peppersack C, Schmidt J, Damm C, et al. (2016) Impact of formulation and operating parameters on particle size and grinding media wear in wet media milling of organic compounds - A case study for pyrene. Advanced Powder Technology 27: 2507-2519. Link: http://bit.ly/2Tnk4xS

3. Zecevic DE, Meier R, Daniels R, Wagner KG (2014) Site specific solubility improvement using solid dispersions of HPMC-AS/HPC SSL - Mixtures. Eur J Pharm Biopharm 87: 264-270. Link: http://bit.ly/2wjVx5f

4. Prodduturi S, Manek RV, Kolling WM, Stodghill SP, Repka MA (2004) Water vapor sorption of hot-melt extruded hydroxypropyl cellulose films: Effect on physico-mechanical properties, release characteristics, and stability. J Pharm Sci 93: 3047-3056. Link: http://bit.ly/2TsSH5M

5. Osawa M, Higashi K, Yamashita J, Moribe K, Yamamoto K, (2014) Characterization of Sulindac Solid Dispersion with Hydroxypropyl Cellulose Prepared by Hot Melt Extrusion. J Pharm Sci Technol 74: 160-169. Link: http://bit.ly/2uK1szX

6. Sarode AL, Malekar SA, Cote C, Worthen DR (2014) Hydroxypropyl cellulose stabilizes amorphous solid dispersions of the poorly water soluble drug felodipine. Carbohydrate Polymers 112: 512-519. Link: http://bit.ly/2TeNC2b
7. Konnerth C, Braig V, Stoyanov E, Lee G, Peukert W (2018) AAPS Poster

8. Kimura K, Shigemura T, Kubo M, Maru $\mathrm{Y}$ (1985) ${ }^{13} \mathrm{C}$ NMR study of O-(2-hydroxypropyl)cellulose. Makromol Chem 186: 61-70. Link: http://bit.ly/3afetR2

9. Desai D, Rinaldi F, Kothari S, Paruchuri S, Li D, et al. (2006) Effect of hydroxypropyl cellulose (HPC) on dissolution rate of hydrochlorothiazide tablets. Int J Pharm 308: 40-45. Link: http://bit.ly/389JvbD

10. Richarz R, Wuethrich K (1978) NOE difference spectroscopy: A novel method for observing individual multiplets in proton NMR spectra of biological macromolecules. J Magn Reson 30: 147-150. Link: http://bit.ly/3anaJgH

11. Kumar A, Ernst RR, Wuethrich K (1980) A two-dimensional nuclear Overhause enhancement (2D NOE) experiment for the elucidation of complete protonproton cross-relaxation networks in biological macromolecules. Biochem Biophys Res Comm 95: 1-6. Link: http://bit.ly/39eAeAH

12. Kumar A, Wagner G, Ernst RR, Wuerthich K (1980) Studies of J-connectivities and selective $1 \mathrm{H}-1 \mathrm{H}$ Overhauser effects in $\mathrm{H} 2 \mathrm{O}$ solutions of biological macromolecules by two-dimensional NMR experiments. Biochem Biophys Res Comm 96: 1156-1163. Link: http://bit.ly/2Tybwoh

13. Liepinsh E, Otting G, Wuerthich K (1992) NMR spectroscopy of hydroxy protons in aqueous solutions of peptides and proteins. J Biomol NMR 2: 447465. Link: http://bit.ly/2VFnTBp

14. Wuerthich K (1999) In Hydration Process in Biology. MC Bellissent-Funel, Eds. IOS Press: Amsterdam 251-258.

\section{Discover a bigger Impact and Visibility of your article publication with}

\section{Peertechz Publications}

\section{Highlights}

* Signatory publisher of ORCID

* Signatory Publisher of DORA (San Francisco Declaration on Research Assessment)

* Articles archived in worlds' renowned service providers such as Portico, CNKI, AGRIS, TDNet, Base (Bielefeld University Library), CrossRef, Scilit, J-Gate etc.

* Journals indexed in ICMJE, SHERPA/ROMEO, Google Scholar etc.

* OAI-PMH (Open Archives Initiative Protocol for Metadata Harvesting)

* Dedicated Editorial Board for every journal

* Accurate and rapid peer-review process

- Increased citations of published articles through promotions

* Reduced timeline for article publication

Submit your articles and experience a new surge in publication services (https://www.peertechz.com/submission).

Peertechz journals wishes everlasting success in your every endeavours.

Copyright: ๑) 2020 Sakamoto N, et al. This is an open-access article distributed under the terms of the Creative Commons Attribution License, which permits unrestricted use, distribution, and r eproduction in any medium, provided the original author and source are credited. 